Revista Digital Año 8. No 11 - Año 2017. -pág. 1-136

ISSN 1853-1393

Resistencia. Chaco. Argentina - 2017

\title{
RELATOS DE HISTORIAS VIVIDAS: RECONCEPTUALIZACIÓN DE LAS BIOGRAFÍAS ESCOLARES DE FUTUROS PROFESORES
}

\section{LIFE HISTORIES RETOLD: RECONCEPTUALIZATION OF SCHOOL BIOGRAPHIES OF TRAINEE TEACHERS}

\author{
Silvia Adriana Branda ${ }^{1}$ - Luis Porta ${ }^{2}$
}

Fecha de recepción: 04-08-2017

Fecha de aceptación y versión final: 31-10-2017

\begin{abstract}
Resumen:
Hay docentes que dejan en sus alumnos marcas profundas que perduran en el tiempo y que luego se manifiestan de diferentes maneras. Se trata de trazas dibujadas por experiencias que conmueven y perduran, que hacen que el alumno se retire de la clase pensando y sintiendo; nos referimos a las huellas que deja aquella práctica docente aggiornada, compleja y reflexiva, que va más allá de simplemente ofrecer un conjunto de hechos, datos y conceptos ya que tienen un entramado subyacente que les da sentido (Maggio, 2012). El presente artículo se desprende de una investigación de corte cualitativo que adopta un enfoque interpretativo, entendido como un proceso de comprensión de los significados cercanos de los propios actores involucrando también la construcción de una lectura constante e integrando los detalles inmediatos con la teoría relevada. Para explorar las huellas docentes en toda su variedad y complejidad, se adopta una perspectiva narrativa, que nos brinda una forma de co-construir la realidad abordándola desde diferentes planos. De esta manera, y mediante el análisis de los textos de campo la narrativa ofrece una particular reconstrucción de la experiencia, a partir de un proceso reflexivo que resignifica lo sucedido o vivido buscando responder el principal interrogante que motivó la investigación: ¿cuáles son aquellas enseñanzas que han dejado su traza en la construcción del perfil profesional de los alumnos del Profesorado de Inglés de la Universidad Nacional de Mar del Plata $(\mathrm{UNMdP})$ ?
\end{abstract}

Palabras-clave: buena enseñanza; biografía escolar; huellas docentes; formación de Profesores de Inglés.

\begin{abstract}
:
There are teachers who leave in their students deep marks that reveal themselves in different ways and last over time. These are traces drawn by experiences that move and last, that make the student leave the class thinking and feeling; we are referring to those traces left by updated, complex and reflective teaching practice, which goes beyond the simple fact of offering data and content as they have an underlying framework that gives them meaning (Maggio, 2012). This article follows a qualitative research that adopts an interpretative approach, perceived as a process of understanding the close meanings of the actors themselves, also involving the construction of a constant reading and integrating the immediate details with the relieved theory. To explore the teachers traces in all their variety and complexity, a narrative

\footnotetext{
1 Doctora en Humanidades y Artes con mención en Ciencias de la Educación (UNR). Magister en Docencia Universitaria, Especialista en Docencia Universitaria, Profesora de Inglés. Docente e investigadora de la Facultad de Humanidades, Universidad Nacional de Mar del Plata (UNMdP). Tucumán 3831 branda.silvia@gmail.com

2 Doctor en Filosofía y Ciencias de la Educación por la Universidad de Granada (España). Docente e Investigador (categoría I) del Departamento de Ciencias de la Educación de la Facultad de Humanidades, de la Universidad Nacional de Mar del Plata, Argentina e Investigador Independiente de CONICET. Castelli 24-11JK luisporta510@gmail.com
} 
inquiry perspective is adopted, which gives us a way to co-construct reality by addressing it from different levels. In this way, and through the analysis of field texts, narrative inquiry offers a particular reconstruction of the experience, from a reflective process that resignifies what happened or was lived seeking answers to the main questions that motivated the research: which are those teachings experiences? who have left their trace in the construction of the professional profile of the students of the English Teaching Education Program of the National University of Mar del Plata (UNMdP)?

Key words: good teaching; school biography; teaching traces; English Teacher Education

\section{Introducción}

Existe un torrente de preguntas asociadas con la forma y el contenido de lo que se denomina requerimientos epistémicos de la enseñanzai (Jackson 2002). Entre estas preguntas que inquietan tanto al docente como a quienes se vinculan con la investigación en educación, se pueden mencionar: ¿qué deben saber los docentes sobre la enseñanza?, ¿hay mucho que aprender?, ¿cómo se genera e interpreta ese conocimiento?, ¿no es gran parte de lo que guía el accionar docente tan sólo una cuestión de opinión?, ¿queda mucho por descubrir o los buenos docentes de hoy en día ya saben la mayor parte de lo que puede aprenderse?, ¿existe en la enseñanza algo más que la mera influencia de la llamada pericia técnica? y en tal caso ¿de qué podría tratarse? Las respuestas que pueden sostenerse son muy paradójicas, ya que algunos docentes dirían que hay mucho por aprender sobre la enseñanza, otros, que hay muy poco. Hay quienes argumentarían que lo que hace falta saber se aprende fácilmente, en tanto otros afirmarían que es una ardua tarea y que la enseñanza sólo puede aprenderse en la práctica, dirían otros. Sucede que los docentes solemos discrepar acerca de la enseñanza y cuáles son sus exigencias en materia de conocimiento y surgen inevitablemente diferencias de opiniones cada vez que se habla de la enseñanza.

Este debate es permanente y existen distintas líneas de pensamiento; por ejemplo, la sostenida por John Dewey quien reconocía que algunos docentes "transgreden todas las leyes conocidas y establecidas por la ciencia pedagógica" (Archambault, 1964: 330). ¿Qué convierte, entonces, en eficaces a estos docentes?: "ellos mismos están tan pletóricos de la ciencia de la indagación, son tan sensibles a todos los signos de su presencia o ausencia, que no importa lo que hagan ni cómo lo hagan, logran despertar e inspirar una actividad mental alerta e intensa en aquellos con quienes entran en contacto" (Archambault, 1964: 330). Asimismo, sostenía que un fuerte espíritu de indagación podía compensar la falta de conocimientos pedagógicos.

Podríamos argumentar, entonces, que existen docentes natos, que tienen tanta habilidad que pueden desempeñarse instintivamente bien en una situación de enseñanza 0 , como expresa Dewey, se comportan de manera tal que compensan cualquier otra cosa que pudieran hacer mal. Ahora bien, ¿estamos dispuestos a considerar la posibilidad de que todos o casi todos los docentes están dotados de uno o más de esos talentos especiales que compensan la falta de formación? Sostiene Dewey que estamos ante una teoría con un supuesto no comprobado y momentáneamente debemos basarnos en la presunción que, si bien existen los docentes natos, éstos complementarían su pericia docente con la debida formación.

Ken Bain (2007) se pregunta si un buen profesor nace o se hace. El autor defiende la posibilidad de que todo docente tiene que aprender a crear condiciones adecuadas para el aprendizaje. Para ello la premisa fundamental agrega el autor, 
es partir de la concepción de la enseñanza desde el aprendizaje y no de la docencia como transmisión y, a partir de dicha concepción, reflexionar sobre la práctica; de esta manera, continúa Bain, gran parte de la condición de ser un buen profesor, consiste en saber que siempre hay algo nuevo por aprender.

Por otro lado, Donald L. Finkel en su libro Teaching with Your Mouth Shut (2000) reflexiona acerca de la importancia de lo que se es y de lo que se hace más allá de lo que se dice- cuando un docente busca que sus estudiantes se interesen por el conocimiento, que lo amen y que lo utilicen de manera honesta. Afirma que la actitud del profesor, el trato, la preparación, la sensibilidad, la dedicación, la escucha, la observación, la puntualidad, el ejemplo, son formas de enseñanza, tanto como la palabra (Finkel, 2000); es decir, no sólo se da clase cuando se explica en voz alta la materia.

Partimos de la premisa de que cada docente está inmerso en un mundo complejo y diverso. En el correr de cada historia escolar y como producto de aprendizajes sucesivos, se van configurando esquemas a partir de los cuales se organizan y significan las experiencias posteriores. De esta manera, estamos ante la presencia de aprendizajes implícitos (Branda, 2014) que son aquellos que asoman como producto de la experiencia escolar vivida. En su rol de alumnos, los docentes aprendieron a enseñar, a ser maestros y a relacionarse con la escuela. En cada práctica hay un aprendizaje explícito que se manifiesta en un contenido o en una habilidad, pero la experiencia en la que se despliega ese aprendizaje deja una marca profunda que se transforma en aprendizaje implícito. Así, aprendemos a organizar y resignificar nuestras vivencias, emociones y pensamientos: conformamos hábitos.

En función de esto, estamos entonces frente a los siguientes interrogantes: ¿Podemos poner de relieve algún rasgo especial sobre las huellas que los docentes dejan en aquellos a quienes enseñan?¿Qué aprendemos de nuestros docentes acerca de nosotros mismos, de los demás y de la vida en general? Este tipo de aprendizaje no se refiere al contenido de una asignatura, sino a algo que va más allá de lo que inmediatamente podemos reconocer. De esta manera, nos desplazamos de los aprendizajes implícitos a lo que Philip Jackson (1999) denomina enseñanzas implícitas ya que no están incluidas en la agenda explícita del docente. Según el autor, ellas toman características y rasgos de aquellos sujetos que nos enseñaron y a quienes recordamos mucho después de haberles dicho adiós. Las enseñanzas implícitas toman forma de cualidades que hacen que estos docentes queden en nuestros recuerdos y nos acompañen a lo largo de nuestras vidas, dejando efectos marcados a fuego. Muchos de nosotros no podemos reconocerlas en forma consciente ya que nacen en nuestro interior a modo de sensaciones y sentimientos que nos cuestan explicar. Estos efectos producen un impacto también en quienes nos dedicamos a la docencia, ejerciendo una gran influencia en el modo de actuar cotidiano profesional.

Las historias vividas en la escuela constituyen, para quienes se dedican a enseñar, una fuente de experiencia que tiene una fuerte impronta que se refleja en la práctica, sobre todo en los docentes nóveles quienes ante la incertidumbre y la ansiedad se basan en experiencias previas como alumnos para configurar sus propios estilos y estrategias de enseñanza (Hargreaves, 1996). Antes de insertarse en la escuela, han vivido una trayectoria escolar donde han aprendido tanto saberes como formas de hacer las cosas y modalidades de ser, ya sea alumnos o docentes. Son numerosas las investigaciones que han resaltado la importancia de 
la biografía escolar previa para quienes enseñan, en particular cuando dan sus primeros pasos como educadores. Por ejemplo, ya en 1975 Maurice Lortie señala que la biografía escolar es el elemento clave para entender la socialización profesional. Sus reflexiones en Schoolteacher (1975) apuntan a las marcas que la vivencia escolar previa deja en los docentes. Ese aprendizaje anterior a la etapa de preparación profesional, despojado de todo lenguaje técnico, transcurre durante muchos años en los que se está en contacto con la escuela y deja su impronta en quienes luego se dedican a enseñar. Por otro lado, Andrea Alliaud (2010) sostiene que el pasaje prolongado por la escuela, forma y actúa en los sujetos a modo de esquemas, configurando las prácticas y representaciones del presente. Por lo tanto, en la escuela vivida podrían encontrarse las semillas de lo que luego se produce y reproduce en la práctica profesional.

Consideramos que la biografía escolar tiene suma relevancia en la construcción de la profesión docente y en nuestra investigación nos centramos en aquellas buenas enseñanzas que dejan una fuerte impronta en los alumnos del Profesorado de Inglés quienes luego, consciente o inconscientemente, las toman al momento de realizar sus prácticas pre-profesionales, "ii recreándolas dentro y fuera del aula. Buscamos categorías interpretativas vinculadas al origen mismo de las enseñanzas implícitas y explícitas, a los sujetos implicados y a las características propias de las prácticas docentes. Nos proponemos sacar a luz aquellas buenas prácticas heredadas interpelando la biografía de quienes están realizando sus residencias docentes porque contribuyen a comprender el accionar profesional y alientan la intervención en los ámbitos de formación.

\section{Desarrollo}

\section{El análisis narrativo de las biografías escolares}

La educación, entendida como un proceso social protagonizado por sujetos que se desarrollan relacionalmente en su peculiar situación, supone ciertos a priori históricos [...] las representaciones de los sujetos acerca del mundo y de sí mismo, el grado de desarrollo de conocimiento científico y tecnológico, los modos subjetivos de vivir y del pensar en la compleja trama de la cultura, condicionan las prácticas educativas y sus modos de concreción.

Violeta Guyot

En la comunidad de investigadores contemporáneos, afirma Goodson (2017), se puede percibir un consenso: estamos viviendo en una era de narrativaiii pero, agrega, la realidad es más compleja aun, ya que si bien los relatos de vida son parte de una moneda corriente, estamos entrando en un período muy particular, en el de las narrativas en pequeña escala. En el pasado, hemos tenido una serie de grandes narrativasiv de intenciones humanas y progreso que han crecido exponencialmente a partir de la mitad del siglo IXX. Sin embargo, hacia fines del siglo XX hemos presenciado el colapso de las grandes narrativas para comenzar a sumergirnos en aquellas de pequeña escala, más individuales (Goodson, 2017). De esta manera, continúa el autor, estamos presenciando una era de pequeñas narrativas.

Los sujetos cuentan sus historias con un propósito y los detalles biográficos se usan para contextualizarlas y compararlas con otros sucesos. En este sentido la narrativa describe cómo el pasado se relaciona con el presente; organizan su vida y experiencias por medio de los relatos, y al hacerlo les encuentran sentido (Atkinson 
y Coffey, 2003). Así se preguntan a sí mismos, cómo comenzó todo y cómo llegaron hasta donde están hoy (Atkinson y Coffey, 2003). Nuestro análisis de los textos de campo considera a sus relatores como co-autores de las tramas mediante las cuales reconstruyen su biografía escolar.

La narrativa comunica el punto de vista del narrador, incluye, en primer lugar, por qué vale la pena contarla; además de describir lo que sucedió, las narrativas también expresan emociones, pensamientos e interpretaciones. El discurso narrativo pone énfasis en la singularidad de cada acción o suceso humano en lugar de sus propiedades comunes (Bruner, 1997). Cuando alguien cuenta una historia construye, representa y le da forma al self ${ }^{\nu}$, a la experiencia y a la realidad. La narración es una acción activamente creativa en la que se construye la realidad dentro de la comunidad del narrador, el entrono local, la pertenencia social y organizacional y la ubicación cultural e histórica.

La historia de vida personal es un instrumento individual si se lo separa del contexto ya que focaliza en la propiedad única de la individualidad personal y las circunstancias, al hacerlo puede ignorar u opacar las circunstancias colectivas y los movimientos históricos, es por esto, afirma Goodson (2017), que las historias de vida deben ser construidas en una circunstancia histórica específica y en determinadas condiciones culturales. Además, el guion personal está inscripto en el amplio marco social que lo define, de esta forma, debe ser ubicado culturalmente en búsqueda de comprensión. También deben ser comprendidas en relación al tiempo y la periodización, es decir, su contexto histórico. Finalmente, hay un tiempo personal marcado por la manera en que las personas desarrollan fases y patrones de acuerdo con sus sueños personales, objetivos o imperativos en el recorrido de la vida (Goodson, 2017). En este sentido, el autor recomienda organizar la información de manera de no caer en la trampa de individualización, guion vacío y descontextualización tratando de reconstruir cada historia dentro del período histórico y temporal y su ubicación histórica contextual.

La investigación que alimenta este artículo se gestó en el marco de las residencias como dispositivo de práctica inicial y los alumnos que participaron en ella estaban realizando sus prácticas pre-profesionales. En el análisis debemos recordar que éstas se ven atravesadas indefectiblemente, por un lado, por la impronta evaluativa que, en términos de calificación, tiñe toda instancia (Edelstein, 2015), por el otro, por la presencia de otros -tutor, pareja pedagógica, profesor del curso e investigadora- ajenos al aula, que de alguna manera condicionan al practicante. Las prácticas docentes en sí implican "poner el cuerpo; estar al frente, de frente, enfrente: sostener y sostenerse; exponer y exponerse a otros [...]" (Edelstein, 2015: 191), provocando en los practicantes una gran sensación de vulnerabilidad.

Organizamos el análisis de la información en dos momentos, que no impiden el manejo recursivo de la información, por el contrario, favorecen el recorrido cíclico en la interpretación. En el primero trabajamos verticalmente con cada historia coconstruida recurriendo a todos los textos de campo de cada uno de los participantes. En el segundo, por medio de un análisis horizontal de cada instrumento, atravesado por los relatos de los participantes, nos avocamos a la reconceptualización de las biografías escolares en un paisaje común de socialidad temporalidad y espacialidad (Clandinin y Connelly, 1995) buscando responder las preguntas que guiaron la investigación. Estos dos momentos representan la construcción narrativa densa haciendo uso de la doble hermenéutica que da cuenta 
de la imbricación y de la interpretación que existe entre el saber científico y el saber común. Desde nuestra perspectiva interpretativa rescatamos la hermenéutica como comprensión de lo social, por lo tanto en este análisis nos interesa otorgar significado e interpretar las experiencias humanas por medio de la interacción entre la investigadora y los participantes. Los actores reflexionan y hacen inteligible su mundo, lo significan y lo interpretan. Es así que damos un primer sentido en el análisis de las narrativas, por medio de una red de conceptos poderosos que se van entramando y articulando. Un segundo sentido es el que le otorgamos a través del análisis del relato extenso y co-compuesto originado en el primer momento. Finalmente, el tercer sentido es el que cada uno de los participantes le da a su propia historia con su sello personal de poema, metáfora o imagen que lo representa.

\section{Primer momento: Las historias co-construidas}

Comenzamos nuestro análisis con la voz y los relatos de los narradores para concentrarnos en sus propias historias, distanciándonos un poco del tradicional método orientado por el tema para el análisis del material cualitativo. Así, en lugar de ubicar los temas distintivos en la medida que transcurre la entrevista, escuchamos primero las voces que habitan cada narrativa. Presentamos nuestra co-construcción narrativa de los nueve relatos que surgen de las interacciones con los participantes. Para co-estructurar estas historias desentrañamos la trama, el tejido narrativo (Ricoeur, 2000) de cada una de ellas utilizando sus testimonios recopilados en las entrevistas biográficas (EB) y en las focales (EF), en los relatos escritos (RE), en los registros etnográficos (RET), en las entrevistas flash (EF), en los planes (PC) y en los diarios (DC) de clases de cada uno de los practicantes. Organizamos sus historias siguiendo cuatro dimensiones que nos permiten construir ordenadamente la biografía escolar de cada participante: la afectivoemocional, la institucional, la profesional y los acontecimientos macro-sociales. Inicialmente, reconocemos por un lado, aquellos practicantes que, al elegir el Profesorado de Inglés, deseaban ser docentes y tenían un gusto especial por la lengua inglesa y por el otro a quienes eligieron su carrera por amor al idioma, pero sin tener como meta final la docencia. Así se desprenden dos grandes categorías que enmarcan los dos momentos de análisis el deseo de ser docente y huellas impregnadas por el idioma inglés.

En esta ocasión nos concentramos en el segundo momento y más precisamente en el grupo de participantes que eligieron el Profesorado de Inglés solo por amor al idioma quienes desde niños estuvieron interesados o de alguna manera, sus vidas fueron atravesadas por la lengua inglesa. Ya sea por la influencia de la música, el interés de explorar otras culturas, circunstancias diversas que han experimentado o por algún referente que los ha marcado en su biografía escolar, han cultivado el "sentirse a gusto" con este idioma. Por este motivo eligen el profesorado, no por su deseo de ser docentes ya que, en algunos casos, querían ser traductores, pero ante la inexistencia de la carrera de Traductorado de Inglés en la universidad pública de Mar del Plata, falta de recursos para trasladarse a Buenos Aires o afrontar una universidad de gestión privada, deciden inscribirse en el Profesorado de Inglés. 


\section{Segundo momento: Re-conceptualización de las biografías escolares en un paisaje común de socialidades, temporalidades y espacialidades}

Clandinin y Connelly (1995) aseguran que el conocimiento práctico personal docente se forma desde su experiencia pasada, en la mente y el cuerpo del presente y con los planes y acciones futuras de cada profesional. Agregan que el conocimiento docente está formado y expresado en el complejo contexto en que cada uno se desempeña y utilizan una metáfora para describir esta complejidad, que es la metáfora de paisaje (Clandinin y Connelly, 1995). Mediante esta metáfora desean representar el tiempo, el lugar y el espacio con una idea de expansión y con la posibilidad de que distintas personas, eventos y relaciones se involucren. Esto es, la relación entre personas, lugares y cosas representando un paisaje moral e intelectual. Pensar la vida como una historia es una forma potente de imaginar quiénes somos, dónde hemos estado y a dónde nos dirigimos.

Los relatos capturados en la secuencia de narrar expresan descubrimientos, anhelos, esperanzas, pasión, afán de superación, amor, afecto, sensibilidad, compromiso, reflexividad, espíritu de lucha, empatía, trabajo, antagonismos y búsqueda de cooperación. En este segundo momento reconfiguramos las historias de los residentes a partir de los tres lugares interrelacionados en la narrativa: la temporalidad, la socialidad y la espacialidad, formando así un paisaje común. Realizamos numerosas lecturas a los textos de campo y reconfiguramos las narrativas respetando la voz de cada participante. En la temporalidad encontramos las experiencias pasadas, presentes y sus expectativas personales y profesionales; en la socialidad suben a escena diferentes protagonistas que compartieron la vida de los participantes y en la espacialidad se revelan los lugares donde los estudiantes habitaron, estudiaron, y en el presente residen, trabajan y se forman como futuros docentes. En nuestro interés de interpretar las biografías escolares de los alumnos residentes del Profesorado de Inglés, el paisaje no se puede analizar separadamente porque son sus tres componentes entramados los que van dejando huellas en todo el trayecto vivido. Mediante el trabajo hermenéutico realizado fuimos entretejiendo las voces de cada uno de los participantes con la de la investigadora logrando un análisis que mantiene la frescura y naturalidad de quienes relatan sus vivencias.

En nuestra investigación conceptualizamos por un lado, el paisaje común de aquellos participantes que inicialmente deseaban ser docentes -amor por la docencia- y por el otro, de aquellos quienes comenzaron la carrera solo por gusto por el idioma, sin estar interesados en la docencia -huellas impregnadas por el gusto por el idioma inglés. De esta manera salimos en busca de respuestas a la preguntas que guiaron nuestra investigación: ¿cuáles son las buenas enseñanzas que han dejado su huella en la biografía de los alumnos residentes del Profesorado de Inglés de la UNMdP?, ¿de qué manera los alumnos caracterizan estas enseñanzas?, ¿cómo se manifiestan en su práctica en el aula esas buenas enseñanzas experimentadas? y ¿cuál es la impronta que dejan en la biografía escolar de los practicantes? Tal como mencionamos en párrafos precedentes, nos zambulliremos a continuación en las historias de quienes iniciaron sus estudios solo por gusto por el idioma. 


\section{Huellas impregnadas por el gusto por el idioma inglés}

Nuestros entrevistados Julián, Fede, Lau, Andre y Sol eligen el Profesorado de Inglés pero no deseaban ser docentes. Les gustaba el idioma inglés como medio de socialización y vinculación con la música, el arte y la literatura, deseaban ser traductores.

Al reflexionar acerca de cuáles son las buenas enseñanzas que han dejado su huella en la biografía escolar de estos residentes, encontramos diferentes posturas. Fede declara que, indudablemente, su biografía escolar ha mediado positivamente en su práctica inicial. Uno de los indicios presente en sus propias clases es "la buena relación con la mayoría de mis alumnos" (RE). Considera que cuando sus profesores de la escuela no se relacionaban con los alumnos o no mostraban interés en fomentar una comunicación cordial y fluida con los estudiantes, éstos perdían interés en las clases, "intento comunicarme con mis alumnos en todo momento y trabajar con responsabilidad para favorecer el buen clima dentro del aula" (RE). Lau entiende que "toda biografía escolar deja huella, después uno decide qué copiar y qué no" (RE). Opina que lo más importante en la docencia es "enseñar con pasión, dedicación y llegar al alumno un poco más allá del contenido" (RE) curricular, acercándose a lo personal. Al evocar su biografía escolar Sol rescata haber aprendido mucho a través de lecturas literarias, "ansiaba el momento del año [...] en el que comenzábamos a leer novelas y/o historias en las clases de inglés. Me motivaba leer estos tipos de textos y poder comprenderlos" (RE), como también de películas y canciones, sin embargo, considera que su aprendizaje previo no se refleja totalmente en sus prácticas iniciales ya que si bien utiliza estos recursos en sus clases, no lo hace de la misma manera que lo hicieron sus docentes. Manifiesta que no deben ser usados solamente como entretenimiento, sino que hay que preparar guías que promuevan la comprensión. Sin embargo, admite que tuvo profesores que utilizaban actividades muy variadas en sus clases, y esa dinámica la ha marcado. Andre reflexiona que su biografía escolar ha sido "trascendental" (RE) en la formación de su perfil profesional ya que hubo varios profesores en la escuela secundaria y en el profesorado que la marcaron "de todos algo me llevé [...] muchos docentes dejaron muchas marquitas y algunas irreconocibles" (EB). Al comenzar a transitar el camino de la docencia, sintió que estaba repitiendo o imitando ciertos hábitos propios de algunos profesores suyos "tomé patrones de conducta o formas de enseñar que me habían motivado y comencé a implementarlos en mis clases. Esto me ayudó a generar clases dinámicas y frescas, siendo yo misma y dándome confianza en mi manera de enseñar." (RE) Reconoce encontrarse imitando inconscientemente aquellas actitudes que profesores motivadores han tenido con ella, en ocasiones se escucha repitiendo palabras que no son propias, sino de algún profesor de la secundaria 0 de la universidad. Afirma que su educación ha sido un regalo, encontró personas que "incondicionalmente compartieron sus saberes y me motivaron a sobrepasar obstáculos en el camino. Me parecía injusto no continuar con ese legado." (RE) Por esta razón desea motivar a otros de la misma forma que lo hicieron con ella. Julián opina que las "vivencias escolares son, luego de los vínculos primarios generados en la niñez, las experiencias más fundantes para una persona, es por eso que encaré esta consigna [el relato escrito] primero desde el plano de lo afectivo" (RE). Observa que el desafío intelectual hacia el alumno es una traza que ha heredado de sus docentes, como también lo son el humor, la capacidad de involucrar los intereses de los estudiantes. Siente que hubo materias en el profesorado, como Literatura, por ejemplo, en donde las clases parecían un taller de lectura, sujetas a interpretación. Se generaba un espacio en el que se espera que el estudiante ponga mucho de sí mismo procurando una atmósfera de respeto y valoración del 
aporte del estudiante, de esa manera Julián disfrutó mucho esas materias y asevera que de alguna forma lo influenciaron ya que cuando da clases intenta generar atmósferas similares.

Buscamos ahora interpretar de qué manera los residentes caracterizan estas enseñanzas. Fede evoca algunos de sus docentes, pero no por sus buenas prácticas sino por el contrario, vienen en su memoria aquellos que no tenían una comunicación cordial y fluida con los alumnos y no mostraban interés por relacionarse con ellos, por lo tanto no lograban motivarlos. Asimismo, recuerda una profesora [nombre de la docente del Profesorado de Inglés] quien ejerce la profesión porque le gusta, se apasiona en sus clases "salía con dolor de cabeza, pero por todo lo que había escuchado. Sus clases pasaban muy rápido" (EB). Lau recuerda a aquellos profesores de la universidad que la deslumbraron por su pasión por enseñar, por sus feedback en los que siempre resaltaba aunque sea un aspecto positivo y por sus sabios consejos; uno de ellos fue "no dejes la materia, dejá que la materia te deje a vos" (RE). Esas palabras de aliento le permitieron llegar al final de la cursada. Sol evoca a su maestra de inglés de segundo grado, quien les hizo cantar una canción para practicar greetings ${ }^{\mathrm{vi}}$. Se trataba de unos personajes y decía "Hello, I am Pat, I'm Carol, I'm Michael, I'm Paul. Hello Pat and Carol. Hello Michael, hello Paul" (RE). Sol y sus compañeros de clases cantaban con gusto, sin entender su propósito pedagógico. Hoy, después de tantos años se da cuenta de que el objetivo de la actividad era aprender saludos. Aún recuerda "el sentimiento de alegría" (RE) que le producía. También recuerda a su profesora de inglés de noveno año, quien ofrecía ejercicios muy variados cada vez que aprendían un tema nuevo. Guarda en su memoria el día que la profesora propuso una actividad novedosa para ellos; llevó el horóscopo para descubrir si la descripción que daba de ellos era acertada. Fue la misma docente que luego del ataque a las Torres Gemelas, les hizo buscar información acerca del terrorismo y realizar un proyecto al respecto. Debieron recuperar el significado de la palabra terrorismo y relacionarla con lo sucedido en la ciudad de Nueva York en el año 2001. La docente se ocupó de focalizar en la magnitud del hecho y "hacernos conscientes de lo que el terrorismo implica. Lo tomé como un aprendizaje de un tema real y actual mediante el idioma, y sobre todo en relación con la cultura que estudiábamos." (RE). Con respecto a su paso por el profesorado, evoca a [nombre de la docente del Profesorado de Inglés] del Área Cultural y la describe como una persona que demuestra pasión por su profesión, mucha responsabilidad y compromiso con los alumnos; el primer día de clases le ofreció su dirección de correo electrónico permitiéndoles que la contacten ante cualquier duda que pudiese surgir fuera del horario de clase. Andre recuerda a su profesor de Física, quien les preparó un examen para que lo resuelvan en el Parque de la Costa calculando fricción, gravedad y otros elementos de los juegos, propiciando así un entorno de aprendizaje crítico y natural (Bain, 2007). También su profesora de Literatura y Arte del colegio secundario le ha dejado una huella importante porque la llevaba más allá de sus límites, generando situaciones extremas. "yo sentía que ella me exprimía y demandaba cosas irracionales de mí." (RE); la docente tenía un doctorado en literatura comparada "en ese momento yo no sabía lo que era un $\mathrm{PhD}$, para mí era alguien que sabía mucho [...] recién en la facultad me di cuenta lo mucho que sabía esa mujer [...] me marcó mucho. La odiaba porque me exigía mucho" (EB). Guarda en sus recuerdos las clases de [nombre de la docente del Profesorado de Inglés] por la manera suave y amena que utilizaba para responder a los alumnos, alentándolos a continuar incluso cuando estaban equivocados "como que no sentías que estabas hablando con un docente, sino con una persona nativa que no estaba allí para enseñarte, sino que estaba charlando con vos" (EB). Otra 
profesora que recuerda es [nombre de la docente del Profesorado de Inglés] por su estilo práctico de dar las clases; todas las semanas les preguntaba qué se acordaban del tema anterior y todos sentían que tenían algo para aportar, aunque tal vez lo que decían no era muy relevante, la docente amablemente respondía "sí, está muy bien" (EB) propiciando la participación de los alumnos. Julián recuerda a su profesora de Literatura del secundario quien generó espacios para llevar al aula lecturas, actividades y temáticas relacionadas con los intereses de los alumnos. La docente planteaba consignas de trabajo de manera que, "quien quisiera resolver las actividades con la dedicación estrictamente necesaria para aprender, fijar o practicar los temas, pudiera hacerlo, pero también dando espacio a que, quieres estábamos apasionados por los temas, pudiésemos utilizar el material más ambicioso o buscar formas más profundas o formales de analizar ciertas cuestiones, sobre todo, había mucho lugar para la creatividad y la expresión" (RE). Todo esto, acompañado por la naturaleza "extraordinariamente dulce y generosa" (RE) de esa profesora. También vienen a su memoria las clases de [nombre del docente del Profesorado de Inglés] por su "eminencia [...] porque está bueno darse cuenta que el profesor es bueno en lo suyo. Se agradece como alumno que el que está adelante sepa tanto, que tenga calidad académica y que lo que enseña lo haga con pasión." (EB). Julián asegura que este profesor exuda amor por la literatura, que los alumnos logran darse cuenta de todo el trabajo extra que él realiza y todo lo que no llega a enseñar, que es la persona indicada para el lugar adecuado. También trae el recuerdo de las clases de [docente del Profesorado de Inglés] de donde rescata su sensibilidad, su habilidad para enseñar y su tacto -refiriéndose a su empatía y su trato. Agrega que esta docente "trabaja, trabaja mucho y eso se nota y se agradece" (EB). Siempre estaba disponible para las correcciones agregando una instancia más a los trabajos entregados. En ocasiones, debido a los intereses de los alumnos, las clases derivaban en otro tema diferente al que ella tenía planeado, ella permitía que eso suceda "dejaba fluir la clase" (EB). También tiene presente a la profesora que estaba a cargo del curso cuando realizó su segunda MTE. Es una docente que también trabaja en el profesorado "una santa" (EB) califica Julián porque le ofreció ayuda en sus planes y actividades, aunque ella no estaba obligada a hacerlo. Relata que lo hizo sentirse muy bien, cómodo, lo dejó hacer su trabajo enfatizando que ella estaba allí para ayudarlo, no para evaluarlo.

Las conceptualizaciones emergentes en el análisis de este grupo nos conducen a la actitud del profesor-afectiva e intelectual- y a las decisiones pedagógicas y didácticas que ellos tomaron.

\section{Actitud Afectiva}

- Generan una buena relación con los estudiantes

- Propician un buen clima en la clase de manera cordial y tranquila

- Responden de forma suave y amena

- Llegan al alumno más allá del contenido acercándose a lo personal

- Son generosos, comparten incondicionalmente sus saberes

- Están disponibles para sus alumnos incluso fuera del horario de clases

- Comparten sabios consejos (personales y académicos)

- Son dulces y alegres

Actitud Intelectual 
- Son provocadores, llevan al estudiante más allá de sus límites

- Desafían intelectualmente a la clase promoviendo el pensamiento crítico

- Incitan a sobrepasar obstáculos para seguir adelante, son alentadores

- Asumen mucha responsabilidad y compromiso con su clase

- Enseñan con pasión y dedicación

- Son exigentes

- Tienen capacidad para involucrar los intereses de los estudiantes

- Generan un espacio donde se espera que el alumno ponga mucho de sí mismo estudiante

- Procuran una atmósfera de respeto y valoración del aporte del

- Transforman y emancipan

\section{Decisiones pedagógicas y didácticas}

- Ofrecen variedad de textos reales (no adaptados para la enseñanza de inglés: literarios o de actualidad)

- Promueven un entorno de aprendizaje crítico y natural

- Utilizan canciones y películas como recurso didáctico

- Ofrecen ejercitación variada y novedosa

- Recuperan los temas estudiados en clases anteriores

- Usan el humor como recurso didáctico

- Alientan a los alumnos a buscar información actualizada y situada en problemas reales para realizar proyectos

- Brindan actividades que desafíen intelectualmente al alumno

- Proveen feedback positivo a los alumnos

- Preparan actividades novedosas, actuales, relacionada con la vida de los estudiantes, que provoquen sentimientos: alegría, empatía, interés genuino

- Tratan con temas de interés en la clase y que promuevan el debate

- Propician la creatividad y la expresión propia de cada estudiante

Relacionaremos ahora las conceptualizaciones de este grupo con bibliografía que la sustente.

\section{Acerca de la actitud de los docentes}

Los residentes recuerdan a quienes los llevaban a los extremos, les exigían más allá de sus propios límites. Estos educadores esperan más de sus alumnos, tienen fe en la capacidad de los estudiantes para que consigan lo que se les propone; usan un lenguaje cálido, muestran una gran confianza en los estudiantes y son amables con ellos, estableciendo una relación de respeto mutuo y cordial (Bain, 2007).

Zabalza (2007) hace referencia a la generosidad partiendo de la idea aristotélica de magnanimidad. Asimismo, se define esta cualidad en los buenos docentes quienes se destacan fundamentalmente por el ejercicio moral de la 
enseñanza, generalmente expresado como respeto, generosidad, compromiso, humildad y el interés en el vínculo con el otro (Flores, 2012). Estos buenos maestros agregan un plus a esta última cualidad, que es el entusiasmo y el humor como recurso didáctico (Porta y Flores, 2017).

Recordemos también los principios de particularidad, practicidad $y$ posibilidad acuñados por Kumaramadivelu (2001) que son los pilares de la pedagogía que el denomina Post-method; utiliza el término pedagogía para referirse ampliamente a cuestiones curriculares, de materiales, evaluativas y de estrategias como también a las experiencias socioculturales que, directa o indirectamente tienen influencia en la enseñanza. Estos tres principios están conectados y se involucran mutuamente en una relación cercana en la que la totalidad se destaca ante el valor las partes individuales y juntas forman la esencia de una pedagogía que trata de llevar la enseñanza más allá de los límites cotidianos. El lingüista trata de avanzar en una educación sensible al contexto, basada en la comprensión de las características socioculturales rupturizando la relación entre teóricos y prácticos, permitiendo a los educadores construir su propia teoría desde la práctica -teorías personales-. Cree en aquellos docentes que tienen capacidad para involucrar los intereses de los estudiantes promoviendo en ellos el pensamiento crítico y los valores personales y sociales, como también en aquellos que generan un espacio donde se espera que el alumno pueda gestar y dejar fluir sus propias ideas.

\section{Acerca de las decisiones pedagógicas y didácticas}

Los docentes que los residentes evocan, promueven el valor del pensamiento crítico (Barboni y Porto, 2008), la resolución de problemas, la curiosidad y el compromiso con los asuntos éticos (Bain, 2007). Así, al interpretar las trazas que han dejado en la biografía escolar de los participantes de nuestra investigación retornamos a las ideas del autor quien asevera que la buena enseñanza la brinda un profesor que, a la hora de ayudar a sus estudiantes a aprender, contribuye positiva y sustancialmente, preocupándose por lograr un aprendizaje duradero en las formas de pensar, actuar y sentir de sus alumnos (Bain, 2007); invita a sus estudiantes a hacer esfuerzos intelectuales exigentes, los ayuda a leer de forma más efectiva y analítica mediante textos provocativos, creando un entorno para el aprendizaje crítico y natural (Bain, 2007).

Por otro lado, Maggio (2012) define una enseñanza poderosa, como aquella que apasiona, conmueve y perdura. Sostiene que emocionarse y conmoverse en la clase provoca efectos perdurables, refleja un docente que está involucrado, que le interesa lo que su alumno aprende y cómo lo hace; que desea que sus estudiantes se vayan de la clase pensando y sintiendo (Maggio, 2012). La planificación debe producirse en tiempo presente, de forma contextualizada y aggiornada (Maggio, 2012), ofreciendo una originalidad didáctica y valiosa (Bain, 2007) frente a la tradicional estructura de la explicación que suele incluir una presentación, ejercitación y cierre. De esta manera, continua Maggio, se despierta el interés genuino del estudiante. Así las actividades que los maestros de nuestros participantes prepararon provocaron en ellos sentimientos de alegría e interés genuino. También hicieron uso del humor como recurso didáctico (Porta y Flores, 2014). Los autores sostienen que estos docentes poseen entusiasmo para explicar algunos temas que no son llevaderos o amenos para todos; apelan al humor como disruptor de aquello que es solemne en la clase pero con enseñanza seria; sostienen así la atención y mantienen un clima distendido, buscando ejemplos de la 
vida cotidiana; lo hacen con sensibilidad pedagógica y humana (Porta y Flores, 2014).

Para propiciar la creatividad y la expresión propia de cada estudiante se necesita guiar a los alumnos de manera que sensibilicen la mano en la punta de los dedos (Sennett, 2009), esto es, la práctica adquirida en el aprendizaje en acción, a través de experiencias propias. El sociólogo reflexiona acerca del despertar de una idea y resalta lo sublime de este acto afirmando que "lo sublime sugiere un horizonte ilimitado" (Sennett, 2009: 138). El reto está en preparar un terreno que se cultiva mediante el espacio reflexivo, el desarrollo de habilidades intuitivas y el pensamiento analítico (Atkinson y Claxton, 2002).

Canagarajah (2003) huye de los materiales y textos propuestos por quienes él denomina "Center" -haciendo referencia a los países anglosajones que monopolizan el mercado de libros de textos para la enseñanza de inglés como lengua extranjera o segunda- porque los considera culturalmente inapropiados y que, por meras razones de practicidad, se adoptan en lugar de utilizar aquellos que realmente son útiles para desarrollar dentro de las costumbres locales. Así, alienta a los educadores, básicamente a los Profesores de Inglés, a reflexionar acerca de la agenda oculta de los materiales que el "Centro" provee. Los docentes que este grupo de residentes evocan ofrecen variedad de textos originales, no adaptados para los libros de textos de enseñanza del inglés, sino reales, de actualidad, relevantes para el interés de los alumnos y que promuevan el pensamiento crítico en ellos. Asimismo los alientan a buscar información actualizada y situada en problemas reales para realizar proyectos locales.

Los residentes recuerdan a los docentes que brindan a sus alumnos feedback positivo. La retroalimentación es una herramienta muy poderosa vinculada con el aprendizaje y con el logro académico y su impacto puede ser tanto negativo como positivo (Nicol, 2010). En otras palabras, retroalimentando el desempeño de nuestros estudiantes podemos tanto fomentar como inhibir su aprendizaje (Higgins, et al. 2002). Entonces no basta con proveer feedback para que éste se transforme en un apoyo eficaz del rendimiento y el aprendizaje, hay que pensarlo desde su lugar positivo. Los estudios realizados por Higgins et al. (2002) acerca de cómo los alumnos reciben feedback, hacen hincapié en la forma en que esta retroalimentación es brindada. David Nicol (2010) asevera que debe ser generado como un diálogo y no un monólogo y que la clave está en que la retroalimentación sea rica en detalles, adaptable a las necesidades de los estudiantes y orientada a promover la reflexión. Amanda Ashgar (2010) sostiene que para que la retroalimentación se transforme en una herramienta eficaz en el apoyo del aprendizaje, se debe proporcionarlo tomando en cuenta ciertas características: comenzar leyendo o escuchando el trabajo del alumno desde el inicio al fin sin comentar en los errores para generar una apreciación global; no centrarse en los errores gramaticales u ortográficos como el foco primordial de atención sino que hay que resaltar la buena producción y los aspectos a mejorar. Escribir en el feedback final - o brindar de forma oral- sugerencias acerca de cómo el alumno podría mejorar su trabajo; siempre comenzar resaltando algo que el estudiante hizo bien y así validar su trabajo, reconociendo o identificando los aspectos destacables de su producción; luego de recibir un feedback positivo, el alumno estará emocionalmente preparado para aceptar sugerencias para el cambio (Ashgar, 2010). Nicol (2010) aconseja ser sensible a las necesidades individuales del estudiante y tener en cuenta que algunos tienen que ser estimulados para lograr niveles más altos mientras otros necesitan ser tratados con mucho cuidado a fin de 
no desalentar el aprendizaje y dañar su autoestima. Es esencial, agrega, encontrar un equilibrio para no herir los sentimientos de los estudiantes y proporcionar un estímulo adecuado.

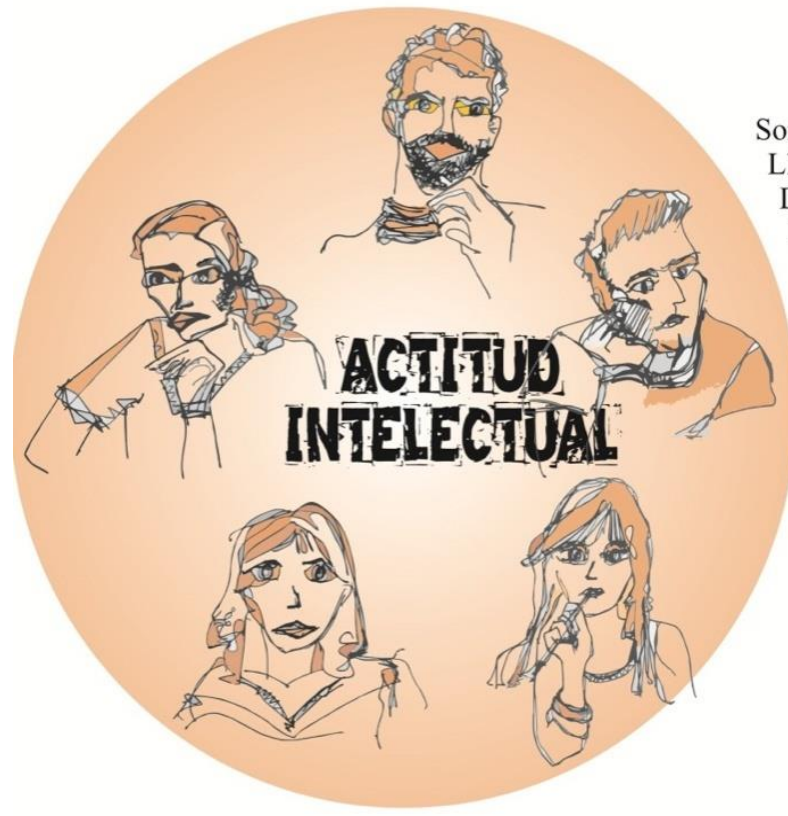

Son provocadores

Llevan al estudiante más allá de sus límites

Desafian intelectualmente a la clase

Promueven el pensamiento crítico

Incitan a sobrepasar obstáculos para seguir adelante

Asumen mucha responsabilidad y compromiso con su clase

Enseñan con pasión y dedicación

Son exigentes

Involucran los intereses de los estudiantes

Generan un espacio donde se espera que el alumno ponga mucho de sí mismo

Respetan y valoran el aporte del estudiante

Transforman y emancipan 


\section{HUELLAS IMPREGNADAS POR EL GUSTO POR EL IDIOMA INGLÉS}

\section{Trazas reflejadas en sus biografías escolares}

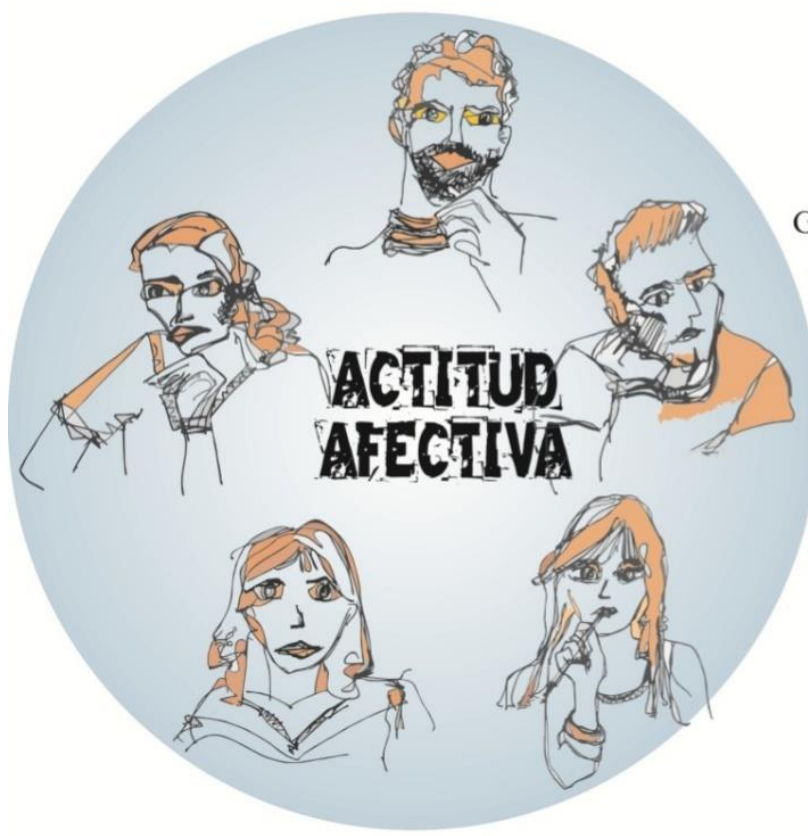

Generan una buena relación con los alumnos Propician un buen clima en la clase de manera cordial y tranquila

Responden de forma suave y amena

Llegan al estudiante más allá del contenido acercándose a lo personal

Son generosos, comparten incondicionalmente sus saberes

Están disponibles para sus alumnos incluso

fuera del horario de clases

Comparten sabios consejos

Son dulces y alegres

HUELLAS IMPREGNADAS POR EL GUSTO POR EL IDIOMA INGLÉS

Trazas reflejadas en sus biografias escolares

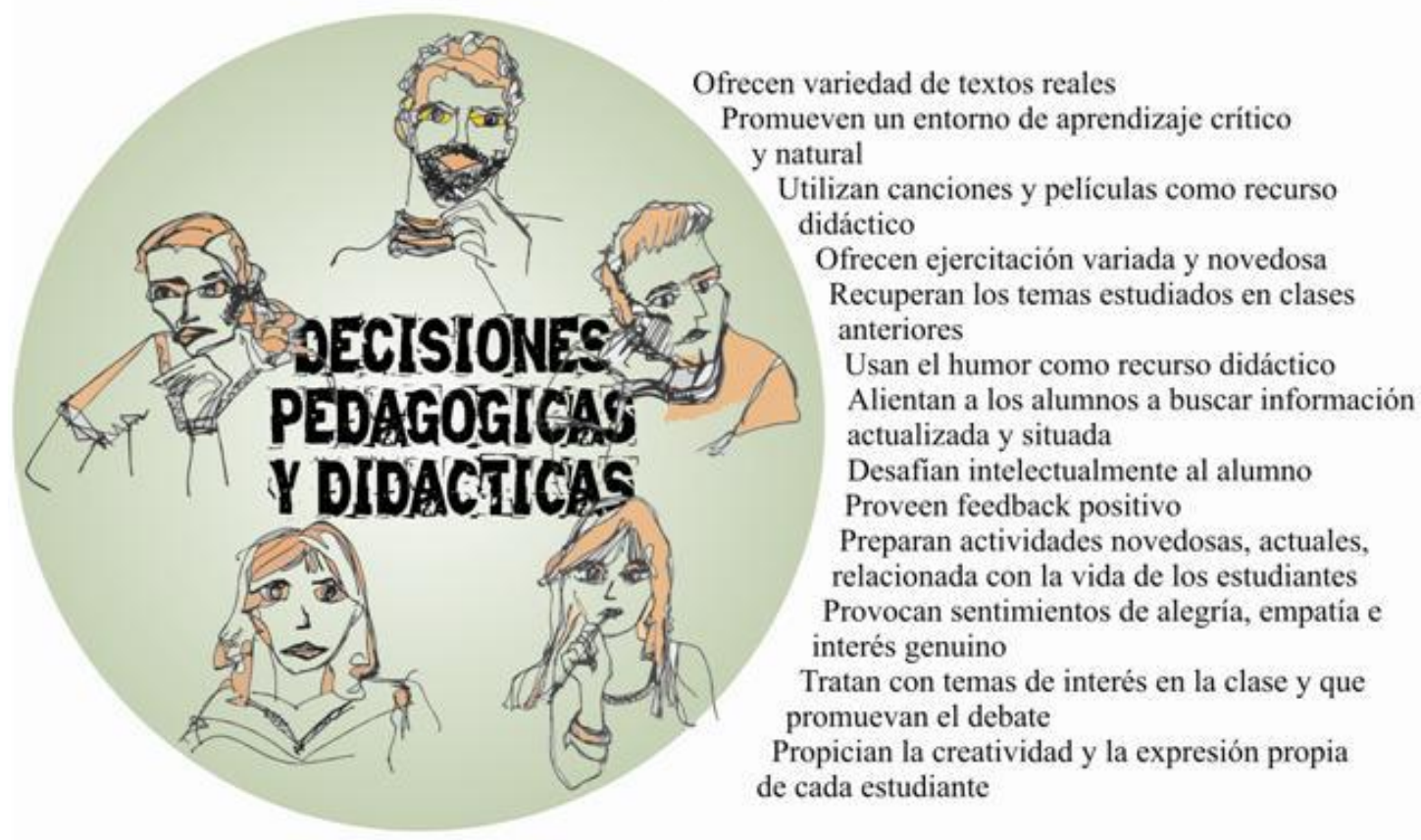

Imagen I: Huellas impregnadas por el gusto por el idioma inglés: trazas reflejadas en sus biografías escolares 
¿Cómo se manifiestan esas buenas prácticas que los residentes experimentaron en la propia? Observamos que Fede tiene una manera cordial y tranquila de dirigirse a los alumnos (RET). Logra generar un buen clima en la clase mediante juegos o actividades que despierten el interés y curiosidad en los alumnos. Su primer encuentro lo inicia dibujando en el pizarrón una caricatura de un conocido jugador de fútbol. Los alumnos debían adivinar de quién se trataba y lo hicieron exitosamente. A su vez, quedaron maravillados por la maestría de Fede para dibujar (RET) y le pidieron que realice nuevas caricaturas, a lo que Fede accedió gustosamente, porque, aunque perdió algunos minutos, los ganó en el clima que logró generar (EF). Lau alienta a sus alumnos en sus clases, recalcando permanentemente que no dejen de intentar. Que siempre se puede comprender un poquito más $(\mathrm{RE})$. Sol reconoce que su experiencia con la literatura mediante una lengua extranjera contribuyó en su formación profesional "ya que hoy en día al pensar en o trabajar con los textos literarios como recurso de enseñanza intento transmitir motivación e interés por el texto elegido" (RE). En sus clases utiliza una narración de Edgard Alan Poe de la sección "Literature Spot" del libro que tienen los alumnos. Así involucra a los estudiantes en un debate con respecto al poder otorgado al dinero en los diferentes contextos sociales (RET). Argumenta haber elegido ese texto no tanto por la riqueza literaria que ofrece, sino por el debate que se genera en el aula (EF). También utiliza canciones, videos atractivos y graciosos, con música pegadiza. En ocasiones, matiza las actividades con un toque de humor. (RET). Andre adopta en sus clases tareas que desafían al alumno. No hace preguntas cuyas respuestas se encuentran fácilmente en los textos o en los videos que presenta, sino que promueve la reflexión tomando como referencia elementos lingüísticos y paralingüísticos (RET). Trabaja con extractos de películas nuevas y provee actividades que demandan esfuerzo cognitivo en los estudiantes. Sus clases son amenas y motivantes enmarcadas por su actitud flexible en el aula, demuestra disfrute en lo que hace (RET), al respecto dice: "entonces se prende un botón y como que... no te digo que sos una actriz, pero sí en un sentido, la actriz fluye [...] se prende una cámara... y ahí sacás..." (EB). Julián recupera la buena relación que ha tenido con sus maestros y profesores y su afán de querer agradarles "Creo que esta huella tan clara de algunos vínculos y experiencias positivos con docentes entrañables impactó negativamente en mi primer acercamiento a la docencia, ya que me preocupaba demasiado por agradar a mis alumnos y por recibir su aprobación." (RE). Sin embargo, con el paso del tiempo, Julián aprendió a encontrar un balance para poder establecer una conexión genuina con los estudiantes. Su experiencia como alumno del profesorado le ayudó a comprender que entablar un vínculo con espacio para el diálogo horizontal, el humor y la confianza, es una muy buena herramienta para incentivar a los chicos a comprometerse con las clases" $(\mathrm{RE})$. Afirma que los rasgos de su biografía escolar que están presentes en sus prácticas tienen que ver con tres aspectos: el humor, la capacidad de involucrar los intereses de los alumnos en el aula y la valoración de sus capacidades intelectuales (EF). Al reflexionar acerca de su propio rol como docente Julián argumenta que enseñar es lo que quiere hacer "mientras le reporte placer y por lo tanto mientras lo haga bien, porque si yo siento que si no lo hago con placer y no lo voy a hacer bien" (EB)

Así es como los docentes dejaron sus huellas y éstas se manifiestan en la práctica inicial de nuestros participantes: 


\section{Actitud afectiva}

- Tienen buena relación con los alumnos estudiantes

- Generan un vínculo que permita un diálogo horizontal con los

- Mantienen una comunicación fluida y cordial, propiciando el buen clima en la clase

- Son alentadores y siembran la auto confianza en sus alumnos estudiantes

- Son flexibles promoviendo así una conexión genuina con los

\section{Actitud intelectual}

- Son dedicados y apasionados en la enseñanza. Disfrutan lo que hacen

- Tienen capacidad para involucrar los intereses de los alumnos en el aula

- Son desafiantes y provocadores: llevan a los estudiantes a un importante esfuerzo cognitivo y a superar los propios límites

- Valoran las capacidades intelectuales de los alumnos

- Muestran un estilo tranquilo al enseñar

- Trabajan la motivación en la clase

Decisiones pedagógicas y didácticas:

- Brindan clases dinámicas y motivantes

- Utilizan el humor como recurso didáctico

- Hacen uso de la confianza generada para incentivar a los estudiantes a comprometerse con las clases

- Usan textos literarios seguidos por actividades variadas

- Promueven debates de temas actuales seguidos por la reflexión

- Se sirven de videos y canciones atractivas y alegres que movilicen el interés del alumno estudiantes.

- Recurren a actividades que involucran los intereses reales de los

Finalmente, deseamos develar la impronta que dejan las buenas prácticas docentes en su biografía y en su práctica inicial. Pare ello daremos lugar a la voz de los residentes. 


\section{HUELLAS IMPREGNADAS POR EL GUSTO POR EL IDIOMA INGLÉS}

\section{Trazas reflejadas en sus prácticas iniciales}

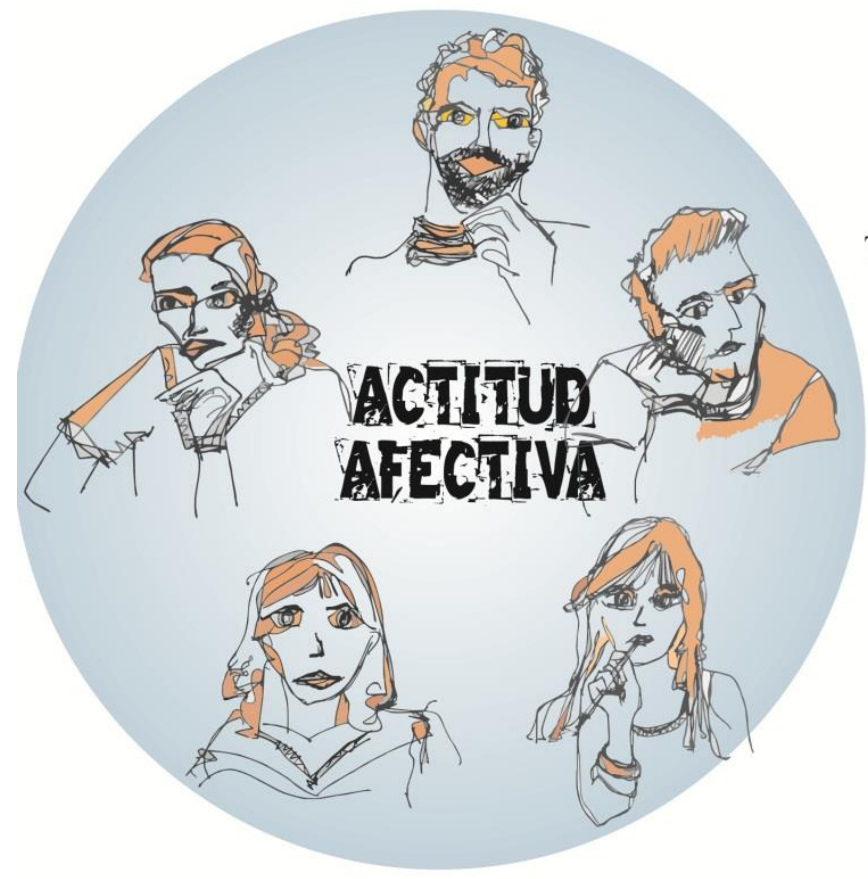

Tienen buena relación con los alumnos

Generan un vínculo que permita un diálogo horizontal con los estudiantes

Mantienen una comunicación fluida y cordial

Propician el buen clima en la clase

Son alentadores y siembran la auto confianza en

sus alumnos

Son flexibles

Promueven una conexión genuina con los estudiantes 

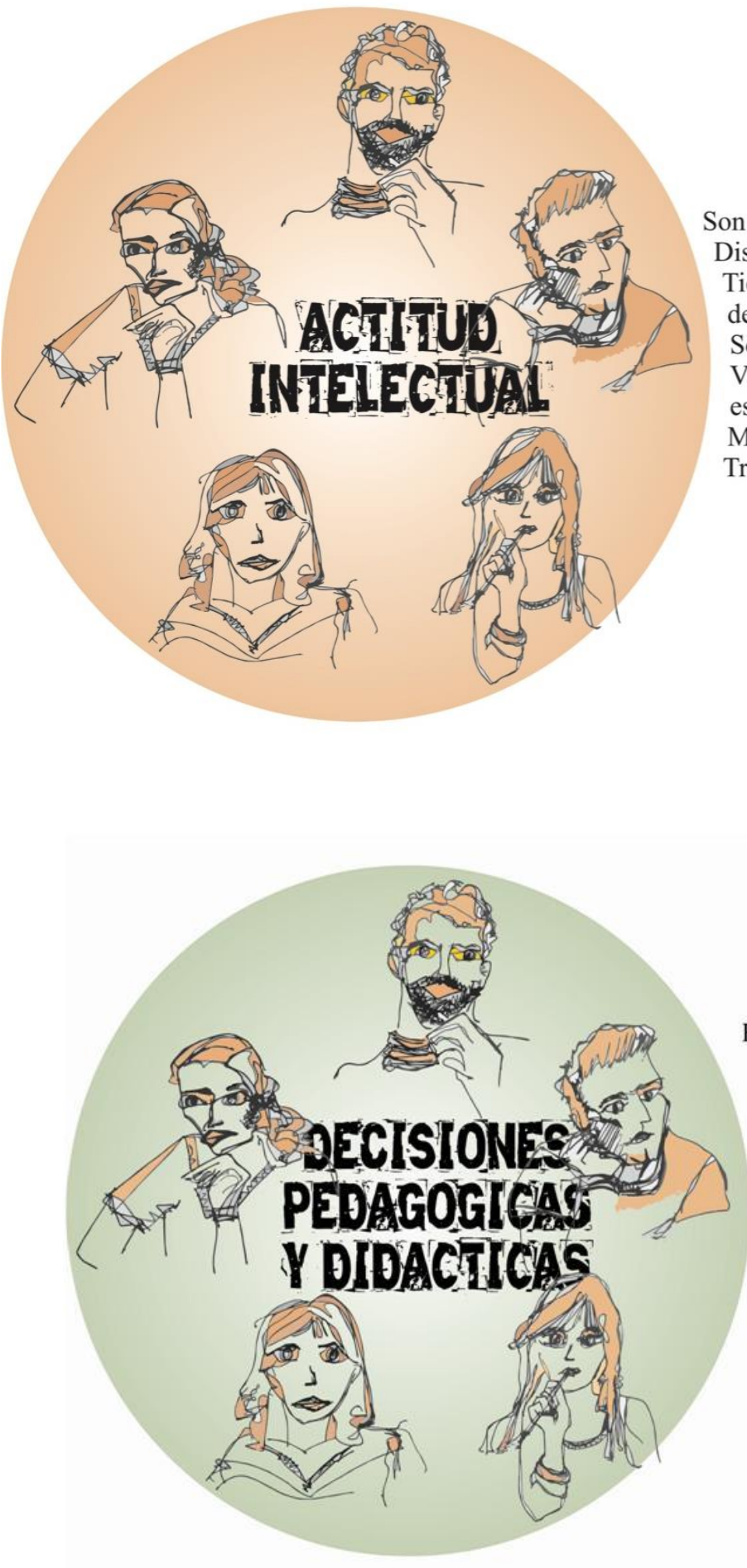

Son dedicados y apasionados en la enseñanza Disfrutan lo que hacen

Tienen capacidad para involucrar los intereses de los alumnos en el aula

Son desafiantes y provocadores

Valoran las capacidades intelectuales de los estudiantes

Muestran un estilo tranquilo al enseñar

Trabajan la motivación en la clase
Brindan clases dinámicas y motivantes Utilizan el humor como recurso didáctico Incentivan a los estudiantes a comprometerse con las clases

Usan textos literarios seguidos por actividades variadas

Promueven debates de temas actuales y reflexión

Utilizan videos y canciones atractivas y alegres que movilicen el interés del alumno Recurren a actividades que involucren los intereses reales de los estudiantes.

Imagen II: Huellas impregnadas por el gusto por el idioma inglés: trazas reflejadas en sus prácticas iniciales. 
Fede

Y... motivación por ahí ponele en la relación con los alumnos [...] con los chicos tengo buen [...] buena relación, me pongo a hablar todo... chistes, cosas así [...] al cuarto año de la mañana voy contento y salen mejores las clases también. [...] lo importante es que los chicos te responden y vos, estar cómodo y que, y que esté, que haya buen clima. Más o menos eso, buen clima y que los chicos respondan y bueno, eso sí [...] que hay un buen ambiente en el aula. (EB)

También sirve hablar con ellos [los alumnos] llevarse bien con ellos, hacer que se sientan cómodos es más importante que enseñar un punto gramatical. (EF)

Lau

Ahora que estoy llegando a mi meta, y que pudo mirar a todo lo que he logrado y crecido, puedo decir que se cumplieron muchas [expectativas]. Tal vez no pude ver eso o no me pude dar cuenta en el trajinar de cursar materias y materias, y muchas veces sentí fracasar. Obviamente, tengo mucho por aprender y mucho por lograr todavía y ojala nunca deje de tener expectativas porque es el motor que me hace seguir (EB).

[...] la calidez de los profesores, por despertar en mí un interés especial, por la pasión con la que se enseña. Eso es lo que guardo en mi recuerdo y aspiro lograr (EB).

Siento que la recompensa más grande es el reconocimiento y el amor de ellos. También lo es el darse cuenta que realmente están disfrutando la clase. Esto me hace disfrutar mucho de la docencia (EB).

\section{Sol}

Cuando empecé a enseñar no tenía tanta experiencia académica digamos, de lo que enseñar implica. Entonces seguía mucho el estilo de enseñanza que me mandaban del instituto, cómo enseñar, en qué enfocarme; lo hacía sin problemas, no reflexionaba mucho al respecto. Pero especialmente ahora me doy cuenta que cuando llega el momento de evaluar no me gusta la manera que tengo que evaluar en ese lugar o al momento de enseñar un tema no me gusta cómo está enfocado, entonces siento el choque entre mis creencias y las creencias del instituto [...] estoy más consciente de qué y a dónde apunto yo (EB).

Me pasa que motivaciones para enseñar las encuentro tanto cuando pienso en los chicos, en el grupo al que le voy a enseñar, pero también cuando pienso en mí, quiero sentirme bien en medio de la clase [...] porque si no siento que me estoy traicionando a mí misma (EB). 
Aspiro a serlo [buena docente], no me gustaría achancharme y decir: bueno, voy a trabajar porque es mi trabajo de todos los días, sino realmente, no me gustaría perder esa motivación de seguir siendo una buena docente (EB). Me gusta mucho ofrecer actividades que impliquen un esfuerzo cognitivo en los alumnos, es decir, que tengan que pensar, ir más allá de lo inmediato y visible. Trato de llevar temas actuales, relevantes, desafiantes para los chicos (EF). Estoy tratando de hacerlo mediante actividades que con las cuales pueden conocerme, preguntar, descubrir parte de mi vida personal y profesional, entre otras. Estoy tratando de hacerlos sentir cómodos, congratulándolos cada vez que puedo (EF).

\section{Andre}

Eso me gustó [experiencia con un alumno que hablaba solo guaraní y un poco de castellano] como darte cuenta que podés hacer un cambio también socialmente, más allá de enseñar inglés... y que...nada... eso, que no sea solo un docente de lengua, de inglés (EB).

Sí, también como dice ella [Mercedes], los recuerdos de profesores que hicieron cosas que te gustaron. A mí, que me gustaron. Cosas que me gustaron que... dije: esto me gustó como me trataron, los voy a tratar igual. Como que no se... esas cosas (EB).

Lo que importa son las preguntas de los chicos, no solo lo que vos tenés para enseñar. Si surgen preguntas que son preguntas que se realizan... genuinas y que te llevan a algo (EB).

El vínculo... la recompensa..., siento que soy uno de esos bichos raros como hay muchos acá del profesorado, que va que cuando alguien aprendió algo de vos y te lo dice y lo usa en un contexto real y es como... Ah... te sentís re, re feliz. Y no lo podés explicar, porque imagino que a mucha gente no le pasa eso de sentir felicidad, o sea con lo difícil que es sentir felicidad, que sientas felicidad con una pavada [...] a veces me asombro cuando me doy cuenta que aprendieron algo de mí sin que yo lo enseñe, simplemente por hablar, repetir una frase, algo... (EB).

Es una cosa como que te fluye desde adentro, como que te toca un botón cuando te toca dar la clase a vos, no sé, en mi casa o en el instituto o en la residencia, es como que ves un baile automático, yo siento eso, como que se prende y automáticamente me sale algo, y lo disfruto y estoy en el momento y soy. Y no sé, lo he sentido por ejemplo en Residencia II, en mi primer día de clase, que vos decís, estás re nervioso y es como que no sé, yo... vos viniste ese día, yo sentí como que se tocó un botoncito y... arranqué a dar la clase sin ningún problema, como si la hubiera dado un montón de veces. Y te disfrutás y... te evadís de la 
realidad, porque por ahí tenés un montón de problemas y no podés estar pensando en eso, o mostrarle a los chicos eso (EB).

\section{Julián}

Me gustaría que más allá del nivel de conocimiento que yo haya podido adquirir y transmitir, que mis estudiantes se den cuenta que a mí me gusta lo que hago y que lo hago con pasión (EB).

Bueno, yo creo que cuando uno se siente más seguro... se anima a más cosas también... por ahí sí, si uno, si uno cuando está arrancando se siente inseguro... si bien yo como te dije para no desmentirme con lo que dije antes, si bien yo me sentía formado y sentía que tenía las herramientas, bueno, la ten... la tensión de las primeras veces siempre está, entonces uno por ahí va con lo que sabe, va con lo probado, con lo seguro. Por ahí en el sentido, en el que más me desempeño es en el que ahora me ... me animo a probar cosas diferentes, me animo a ... iqué sé yo! Me animo a hacer juegos, y sí, sabiendo que puedo, puedo manejarlo (EB).

Cuando noto que, que los alumnos se paran a preguntar algo por ahí, una pregunta que yo no había pensado que me iban a hacer, que quiere decir que fueron más a fondo; o una pregunta que me, me, me lleva a mí a hacer una nueva explicación o a ir yo más a fondo sobre una explicación que ya había dado, eso me motiva un montón... o sea cuando noto que están ahí, que están involucrados, que están presentes. Es algo [la docencia] que aprendo día a día [...] creo que todavía tengo mucho para mejorar y sí, creo que voy a ser un buen profesor, sí (EB).

Si bien yo pienso, cuanto más me forme, cuánto más yo estudie y cuánto más me especifique o especialice mis conocimientos y mi carrera, más voy a llegar a, hacia el lugar donde, donde yo me sentiría realmente cómodo, y donde yo me sentiría intelectualmente estimulado, bien...(EB).

Recordemos que este grupo de residentes eligen el Profesorado de Inglés solamente por el gusto al idioma. De esta manera surgen nuevos interrogantes ¿cómo descubren que les gusta la docencia? y ¿en qué etapa de sus carreras se devela esta inclinación?

A Fede le gustaba inglés y dibujar. Él quería ser traductor, pero comenzó el profesorado porque no podía costearse los estudios en una universidad privada para seguir traductorado. Cuando comienza a cursar las materias del Área de Formación Docente y a hacer las prácticas le "empezó a gustar dar clases y... bueno ahora... y hasta ahora creo que no me gustaría ser traductor [...] ahora no" (EB). 
Al cursar su primer año en el Profesorado de Inglés, Sol nota que no le satisface lo que está estudiando, entonces se pasa a Psicología donde cursa algunas materias. Pero esta segunda elección tampoco la convencía y decide volver al Profesorado de Inglés con la idea de avanzar un poco para luego continuar con el traductorado en otra ciudad. Sin embargo, al iniciar sus prácticas iniciales con las MTE se dio cuenta que disfrutaba dar clases y el contacto con los alumnos "es como que ahí cambio la perspectiva, y digo bueno, no es, no es grave " (EB), y lentamente, con las MTE y las residencias, se fue involucrando cada vez más hasta descubrir que le gustaba la docencia. Sus prácticas docentes iniciales y su primer trabajo en una institución educativa le brindaron "mucha satisfacción [...] recuerdo volver a casa contenta porque no solo había disfrutado la clase sino porque también había logrado un vínculo con los alumnos." (RE). Asimismo, recuerda el placer que le producía observar el avance o la motivación en sus alumnos. Afirma que en esas experiencias se reflejan lo aprendido en el profesorado, se nota la preparación recibida.

Andre encuentra el gusto por la docencia cuando comienza a cursar las materias del Área de Formación Docente. Ella ya había dado clases en forma particular antes de comenzar con el profesorado, pero lo hizo como una manera de generar un ingreso, no por el placer de enseñar, sino porque tenía un buen manejo del idioma. Inicia el profesorado y vuelve a dar clases particulares "y ya era otra cosa. Porque ya tenía un... sentido mi vida, o sea, ya estoy haciendo el Profesorado de Inglés" (EB). Cuando comienza sus prácticas iniciales se da cuenta que dar clases es más complejo de lo que ella creía (EF) y le empieza a gustar el desafío.

Lau admite que el amor por la docencia, que en un principio estaba dormido, lo comienza a sentir con el paso de los años, con docentes que dejaron su marca en ella, sobre todo cuando comenzó a enseñar.

Julián reconoce haber empezado el Profesorado de Inglés con la intención seguir estudiando en otro lado para hacer el Traductorado. Tenía muy en claro que no se veía en el ámbito empresarial ya que "ideológicamente no era lo mío. Contribuir a esa máquina de hacer dinero, no me siento cómodo, no siento que me deje nada a mí ni nada a los demás" (EB). Surgió la idea educación como un servicio. Se vio a sí mismo como docente de escuela pública, no tanto en escuelas privadas. Le "empezó a cerrar la idea de la docencia como esto de recibir una paga a cambio de ofrecerle algo a otro" (EB). Se siente cómodo con esta profesión a partir de su paso por las materias del Área de Formación Docente, se afianzó su imagen como profesor. Inicia su camino como docente en la escuela pública aun siendo alumno del profesorado "y bueno, me empezó a gustar" (EB).

\section{A modo de cierre}

En el primer momento del análisis de la información, recorrimos la biografía escolar de cada residente que participó en esta investigación, entramándola desde las dimensiones afectivas, profesionales, institucionales y macro-sociales que atraviesan. El trabajo recursivo realizado, guiado por todos los textos de campo, nos permitió co-construir sus historias escolares para poder descubrir a cada uno de ellos, conocerlos más íntimamente, develar sus pasiones y sus temores. Asimismo, obtuvimos el andamiaje necesario para el segundo momento, la reconceptualización de las biografías escolares en un paisaje común de socialidad, 
temporalidad y espacialidad (Clandinin y Connelly, 1995) buscando responder las preguntas centrales que guiaron la investigación: ¿Cuáles son las buenas enseñanzasvii que han dejado su huella en la biografía de los alumnos residentes del Profesorado de Inglés de la UNMdP? ¿De qué manera los alumnos caracterizan estas enseñanzas? ¿Cómo se manifiestan en su práctica en el aula esas buenas enseñanzas experimentadas? ¿Cuál es la impronta que dejan en la biografía educativa de los practicantes? En la medida que fuimos interpelando cada uno de estos interrogantes, contrastamos los hallazgos con bibliografía relacionada con el campo disciplinar. Recordemos que el análisis fue sustentado por el proceso de cristalización -que nos habilitó a recrear en todo el recorrido, distintas experiencias que se reflejan al exterior y refractan dentro de sí mismas permitiendo emerger trazas impregnadas en toda la biografía escolar de nuestros participantes. Estimamos que la creatividad y el análisis se dan conjuntamente. Esto involucra la subjetividad, la imaginación, las emociones de los residentes y de la investigadora que no deben ser acalladas en pos de una rigurosidad de análisis, ya que no son condiciones excluyentes. Asumimos la cristalización como la forma de validez más adecuada para el proceso de interpretación ya que permite conocer la perspectiva de cada uno de los participantes co-creando, junto con la investigadora, las historias en ese diálogo permanente y recursivo que se origina y se afianza durante todo el proceso de investigación.

En la medida en que los practicantes pudieron reconocer las fuentes de sentido de sus prácticas, lograron visualizar otras formas de interpretarse y pudieron considerar su propio sistema de creencias y de actitudes. Valoramos el aporte de cada uno de los participantes y deseamos destacar las huellas recogidas en esta investigación, individualizándolos. Para ello diseñamos una imagen que recrea las conceptualizaciones personales de quienes eligieron sus caminos por el gusto que sentían por el idioma (imagen III) entrecruzándolas con la de los otros participantes. Esta imagen que aquí presentamos busca representar una parte fundamental del trabajo realizado en la investigación concentrando las marcas impresas a fuego en la biografía escolar de los practicantes, que lograron develar en durante el trabajo de campo y vieron luego reflejadas en sus propias prácticas. 


\section{HUELLAS IMPREGNADAS POR EL GUSTO POR EL IDIOMA INGLÉS}

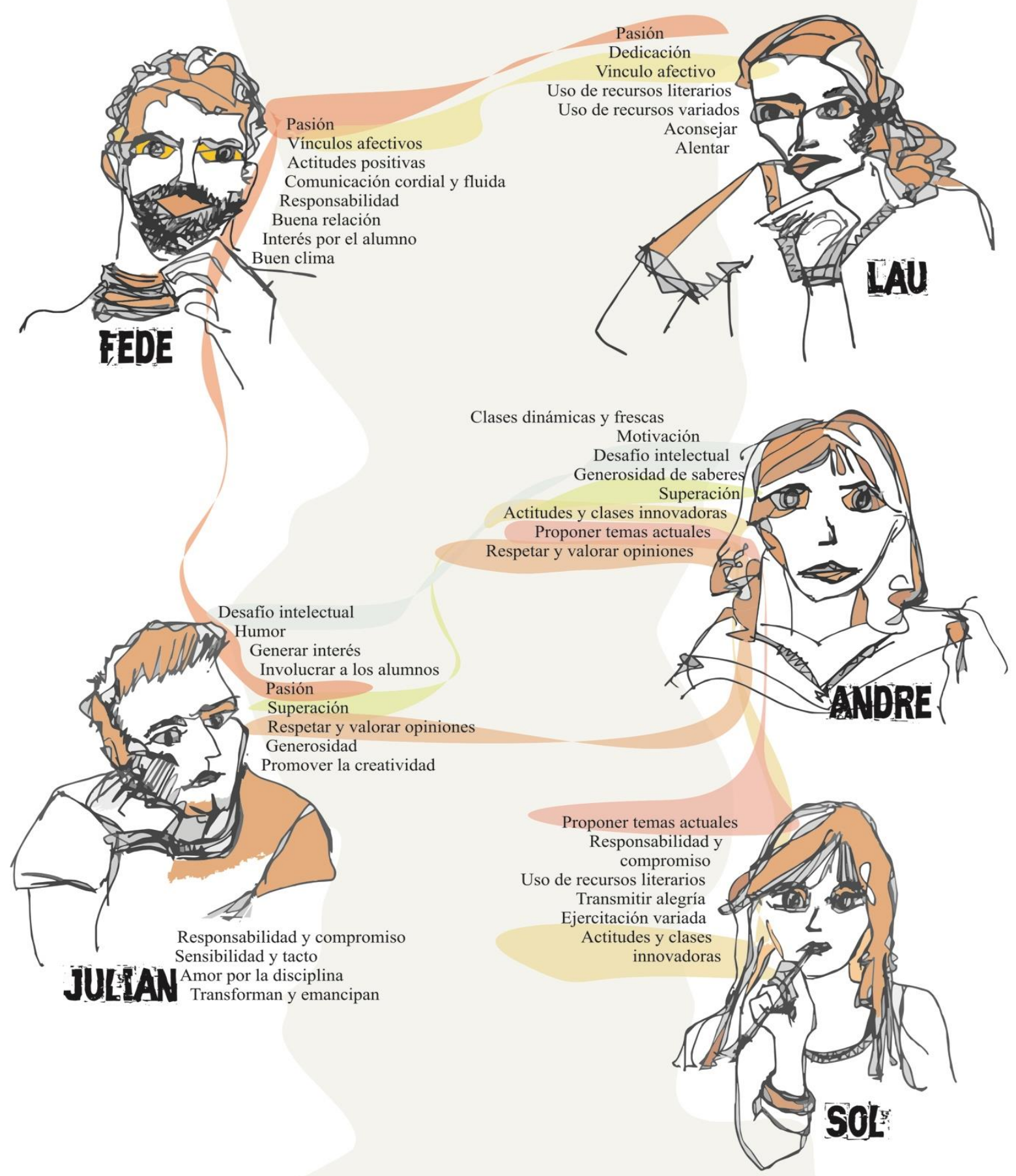

Imagen III: Huellas impregnadas por el gusto por el idioma inglés. Conceptualizaciones individuales y entramadas. 


\section{Referencias}

Alliaud, A. (2010). La biografía escolar en el desempeño profesional de docentes noveles. Proceso y resultados de un trabajo de investigación. En Wainerman, C. y M. Divirgilio (Comps.). El quehacer de la investigación en educación. Buenos Aires: Manantial, 163-178.

Ashgar, A. (2010). Reciprocal peer coaching and its use as formative assessment strategy for first year students. Assessment and Evaluation in Higher Eductaion, 35 (4).

Atkinson, T y G. Claxton (2002). El profesor intuitivo. 1ra Ed. Barcelona: Octaedro.

Atkinson, P y A. Coffey (2003). Encontrar sentido a los datos cualitativos. Colombia: Editorial Universidad de Antoquia.

Archambault, D. (1964). John Dewey on Education. New York: Random House.

Bain, K. (2007). Lo que hacen los mejores profesores universitarios. 2 $2^{\mathrm{a}} \mathrm{Ed}$. Barcelona: Universidad de Valencia.

Bruner, J. (1997). La educación, puerta de la cultura. Madrid: Visor.

Canagarajah, S. (2003). Resisting Linguistic Imperialism in English Teaching. Oxford: OUP.

Clandinin, D.J. \& Connelly, F.M. (1995). Teachers' professional knowledge landscapes. New York: Teachers College Press.

Edelstein, G. (2015). Formar y formarse en la enseñanza. Buenos Aires: Paidós.

Finkel, D. (2000). Teaching with your mouth shut. Michingan: Boynton/Cook Publishers.

Goodson, I. (2017). The Rouledge international book on narrative and live history. London: Rouledge

Hargreaves, A. (1996). Profesorado, cultura y postmodernidad Madrid: Morata.

Higgings, R., Hartley, P., y Skelton, A. (2002). The conscientious Consumer: reconsidering the role of assessment feedback in student learning. Studies in Higher Education, 21 (1): 53-64.

Jackson, P. (1999). Enseñanzas implícitas. Buenos Aires: Anorrortu.

Jackson, P. (2002). Práctica de la enseñanza. Buenos Aires: Amorrortu.

Kumaravadivelu, B. (2001). Towards Postmethod Pegagogy. TESOL Quarterly, 35 (4): 537-556.

Sennett, R. (2009). El Artesano. Barcelona: Anagrama.

Maggio, M. (2012). Enriquecer la enseñanza. Los ambientes con alta disposición tecnológica como oportunidad. Buenos Aires: Paidós. 
Nicol, D. (2010). From monologue to dialogue: improving written feedback processes in mass higher education. Assessment \& Evaluation in Higher Education., 35 (5), August: 501-517.

Porta, L. y Flores, G. (2017). La hospitalidad en profesores memorables universitarios. Revista de Estudios y Experiencias en Educación, abril: 15-31.

Zabalza, M. A. (2007). Competencias docentes del profesorado universitario. Madrid: Narcea Ediciones.

\section{Notas}

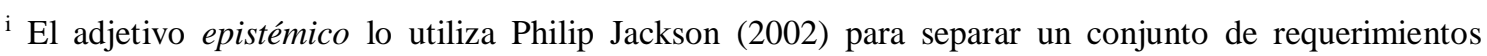
relativos a los conocimientos que deben poseer los docentes, de otros que, como alternativa podrían concitar la atención de quien procure comprender la tarea de enseñar en su totalidad.

ii Utilizaremos el término "práctica pre-profesional" para referirnos a la práctica inicial que realizan los alumnos del Profesorado de Inglés de la UNMdP, durante la cursada de las asignaturas del Área de Formación Docente.

iii Goodson las denomina "age of narrative".

iv "Grand narratives" (Goodson, 2017).

" Susan Chase utiliza el término self-en inglés, sí mismo- para referirse al narrador.

vi "Saludos".

vii Entendemos por "buena enseñanza" aquella en la que el docente participa en la educación de otro ser humano al preguntarse qué acciones docentes pueden justificarse, basándose en principios morales que son capaces de provocar acciones y cambios en los estudiantes Fenstermacher (1989). 